\title{
The short- and long-term impact of an incentive intervention on healthier eating: a quasi-experiment in primary- and secondary- school cafeterias in Brazil
}

\author{
Claudio M Ferreira ${ }^{1,2, *}$, Rafael Goldszmidt ${ }^{1,2}$ and Eduardo B Andrade ${ }^{1,2}$ \\ 'Brazilian School of Public and Business Administration, Fundação Getulio Vargas, Rua Jornalista Orlando Dantas \\ 30, Rio de Janeiro, RJ 22231 -010, Brazil: ${ }^{2}$ Center for Behavioral Research, Fundação Getulio Vargas, Rio de \\ Janeiro, RJ, Brazil
}

Submitted 5 June 2018: Final revision received 26 November 2018: Accepted 10 January 2019: First published online 8 March 2019

\begin{abstract}
Objective: To assess the short- and long-term effectiveness of a lottery incentive intervention to promote the purchase of healthy products in school cafeterias. Design: A quasi-experiment in which students' purchases in intervention schools were analysed in a pre-post analysis and also compared with a control school in a difference-in-differences model. A hierarchical linear model assessed the mean number of promoted healthy products purchased daily per participant before (twenty-six weekdays), during (nine weekdays) and after (twenty-eight weekdays) the intervention period. Sex, age and prior purchasing behaviour served as covariates.

Setting: Convenience sample of school cafeterias using a debit-card payment method that allowed for the assessment of students' purchasing behaviour.

Participants: Students who used the pre-paid card to buy snacks at the school cafeteria. A total of 352 students (208 in intervention schools and 144 in control school) were included in the final analyses.

Results: The incentives programme significantly increased the purchase of promoted healthy products during ( $v$. before) the intervention period in intervention schools $(P<0 \cdot 001)$, especially among younger children $(P=0.036)$. Among the students who purchased the promoted healthier products during the intervention, there was an increase in total number of purchased products (healthy non-promoted, but also of less healthy products). Sex and past consumption behaviour did not influence the response to incentives in the short term. On average, no long-term effect was observed.

Conclusions: Long-term and negative spillover effects must be taken into consideration for a complete understanding of the effects of incentives on healthier eating.
\end{abstract}

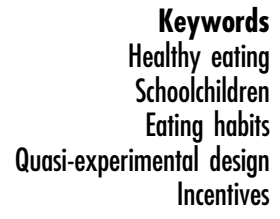
Schoolchildren Eating habits Incentives
Children are failing to meet the recommended daily servings of fruits and vegetables ${ }^{(1)}$, which is in sharp contrast with their frequent consumption of energy-dense, micronutrient-poor foods ${ }^{(2)}$. They are also becoming overweight and obese over the years, a trend partly attributed to unhealthy eating habits ${ }^{(3,4)}$. In Brazil, as in many developing countries, the prevalence of obesity has increased significantly in the past 40 years. Between 1974 and 1997, the prevalence of overweight Brazilian children and adolescents (i.e. 6-18 years old) more than tripled from $4 \cdot 1$ to $13.9 \%{ }^{(5)}$. The latest most comprehensive assessment of health indicators in Brazil revealed a $23.7 \%$ prevalence of overweight and $7 \cdot 8 \%$ of obesity among adolescents aged
13-17 years. Furthermore, the prevalence of overweight and obese teenagers is significantly higher in private compared with public schools ${ }^{(6)}$. Not surprisingly, the shortterm health problems related to childhood and adolescent obesity are increasing in the country ${ }^{(7)}$.

Attempts to counteract the rise in prevalence of overweight and obesity abound, and children represent an intuitive target for health promotion efforts. Eating patterns established in childhood tend to persist throughout life ${ }^{(8)}$. In addition, obesity in children progresses slowly and is often attributed to small changes in energy balance. Thus, obesity prevention in children should need proportionally small efforts ${ }^{(9)}$. Importantly, the school is the location 
where: (i) children and teens spend most of their time when they are away from home ${ }^{(10)}$; (ii) an educational environment and a powerful social network of teachers and peers are in place ${ }^{(11,12)}$; and (iii) class schedules and daily routines create recurring context cues ${ }^{(13)}$. These characteristics position schools as rather promising environments for the implementation of interventions designed to promote healthier habits ${ }^{(14)}$.

Among the host of possible health-related interventions, economic incentives have stood out as a plausible device ${ }^{(15-17)}$ based on their ability to align short- and longterm benefits. Although intuitively appealing, the impact of economic incentives on healthy food intake remains unclear, particularly in the long run. A recent systematic review of twenty-eight studies that used economic incentives to promote healthier eating in schools revealed that, in the short term (i.e. during the intervention period), the interventions proved successful in general ${ }^{(18)}$. However, the overall effect was less convincing in the long term (i.e. after the intervention period). Indeed, while some more recent studies have observed a lasting post-intervention effect ${ }^{(19-22)}$, others observed a clear diminishing effect over time ${ }^{(23,24)}$.

Also, interventions that promote the purchase of less energy-dense snacks might lead to unintended consequences, as the subsequent increase in food consumption. This compensatory behaviour has been observed among children ${ }^{(25)}$ and adults ${ }^{(26)}$ in real-life settings, but not as a result of incentive-based interventions. In addition, experimental studies found mixed results on the effect of energy restriction in compensatory eating ${ }^{(27,28)}$, which calls for further investigation of this issue.

The present study assessed the effectiveness of a private nutrition company's promotion initiative targeted at multiple healthier products available in school cafeterias in Belo Horizonte, Brazil. The nature of the data collection (school cafeteria 'debit cards') allowed for an unobtrusive observation of each individual purchasing behaviour prior to, during and after the intervention. In doing so, the process directly and precisely measured the short- and long-term impact of the incentive and the moderating roles of demographics and past eating habits. In addition, the unique nature of (i) the target healthy products (i.e. healthier snacks allocated from a pool of commonly offered products at the school cafeteria), (ii) the population under investigation itself (i.e. upper-middle-class Brazilian children and adolescents in private primary and secondary schools) and (iii) the availability of data on individual nonidentified consequential previous purchasing behaviour tested the robustness and nuances of the phenomenon.

\section{Methods}

\section{Context and data set}

School cafeterias are virtually omnipresent in Brazilian private schools. A third party most commonly operates the cafeteria, and menus are created under the supervision of a dietitian-nutritionist with the compliance of the school directory board and the parents' council. The cafeteria may have opening hours similar to the school's, and purchases can be made at any time. However, purchases are much more frequent during the morning and afternoon recess breaks.

The payment method varies across school cafeterias. In 2014, a start-up nutrition company based in Rio de Janeiro developed a system to offer a payment solution and nutritional database for private schools in Brazil. Once an agreement is made between the school and the company, all students become eligible users. Parents who choose to adopt this system load money into a pre-paid card that their children use to pay for snacks selected from a touchscreen menu installed in customized totems in the school. The device prints a ticket that is exchanged for the chosen products at the cafeteria counter. Purchase data are stored at the individual level. The advantages of this system include: (i) the reduction of cash transactions in the school environment; and (ii) the ability for the school, the company and the parents to monitor the eating patterns of children (e.g. a parent can monitor what is being offered in the cafeteria and what is consumed by his/her child at school). The company also assesses the nutritional value of foods and drinks offered at schools by following the Nutrient Rich Food Index (NRF9.3) nutrient density score $^{(29)}$ and the offerings are classified into three main categories: low (e.g. soft drinks, fried pies, chocolate bars and candies, other ultra-processed items), moderate (e.g. locally prepared sandwiches, baked pies, pizza, chocolate milk) and high (e.g. fruits, natural fruit juices, low-fat snacks made with wholegrain flour) nutritional value.

\section{Intervention and participants}

In an attempt to promote healthier food habits among its customers, the company designed and executed an intervention targeted at students from three schools (hereafter, 'intervention schools') in the city of Belo Horizonte, Brazil. We learned about the intervention only after its execution. Although we did not have any say about the selection of participant schools or the intervention itself (e.g. type and duration), we decided on the design (i.e. the inclusion of a pre-post period and a control condition), the measures (i.e. how to compute the main dependent variable and variables used for robustness checks) and statistical analyses for the present study.

The intervention lasted nine weekdays from 8 September to 18 September of 2015. Intervention schools were selected from the company's pool by the company's chief dietitian-nutritionist using subjective criteria, reportedly 'their engagement and frequency of exchange of information'. The intervention consisted of the promotion of five target products in each school through raffle giveaways. The five products were a combination of food and drink items of moderate (e.g. locally made cheese and 
tomato pastry, chicken pastry, wholegrain cookie) and high nutritional value (e.g. fruit salad, fresh orange juice, apple; for the complete list of promoted products, please refer to Supplemental Table 1 in the online supplementary material).

Each of the participant school cafeterias selected five products of moderate or high nutritional value regularly offered on the menu. Each time students bought any of those promoted items using the pre-paid card system, they received a raffle ticket that could be drawn to win a board game and a credit of R $\$ 15$ (approximately \$US 5) in their pre-paid card account. The raffle was advertised in the intervention schools through posters that were affixed before the start of the promotion (2 September) such that students who were not using the system could join and participate (from 8 September onwards). Each school cafeteria exhibited a case where the raffle tickets should be filed. The winners were drawn from a ballot box on 14 September and again on 21 September, when the prizes (board games) were delivered. The $\mathrm{R} \$ 15$ in credit was later loaded into the winners' accounts.

From the pool of schools that used the company system, we identified one school that had not been treated with the intervention. In addition to being in the same city as the intervention schools, this control school also offered a similar menu, including items that were promoted in the intervention schools, during all the period of interest (see details in the next section).

For the purpose of the present study, a student was considered a participant if he or she made a purchase using the debit-card system anytime during the period of interest, whether or not he or she ever bought a promoted product. The students' ages ranged from 7 to 18 years. Participants were all followed longitudinally and their number did not vary across time periods in the intervention schools.

We obtained ethical approval from our institutional research committee (\#06102015-1701) as well as from the company (Technical Cooperation Term \#09062015) to independently analyse the data. Students' anonymity was preserved. To avoid any potential conflict of interest, no member of the company participated in the analyses or reporting of this, now called, quasi-experiment.

\section{Measures and design}

The outcome variable was the mean number of promoted products purchased daily per participant. Although we measured purchase rather than actual consumption, the former has shown to serve as a rather reliable proxy ${ }^{(30)}$.

Since our research interest focused on the extent to which the intervention increased healthier food purchase in the short term (during the intervention period) and long term (after the intervention period), a pre-post design was implemented. To avoid interferences due to winter vacations (which occurred from 11 July until 31 July), the time frame of interest was restricted to the period between August and October 2015. National holidays and weekends were not considered. The final sample included: (i) an intervention period of nine weekdays, which was the total duration of the promotion and was not determined by the authors; (ii) a preintervention period of twenty-six weekdays, which was retrospectively determined by the authors, having the start of the Spring term as an external constraint; and (iii) a postintervention period of twenty-eight weekdays, which was retrospectively established by the authors to roughly match the duration of the pre-intervention period.

\section{Moderators}

Sex and age represented the main demographic variables of interest. Girls feel more social pressure to stay thin, are more dissatisfied with their bodies because they feel overweight ${ }^{(31)}$ and may start dieting at a very early age ${ }^{(32)}$. Thus, one could expect girls to be more motivated than boys to adhere to an intervention that rewarded choosing a healthier, less energydense snack. Conversely, boys are more likely to take financial risks ${ }^{(33)}$, overestimate the chances of winning ${ }^{(34)}$ and enjoy gambling ${ }^{(35)}$. Thus, one could expect boys to be more attracted to a lottery-based reward than girls.

The impact of age is also possible, but the direction is likewise unclear. Although younger children might find it difficult to understand and respond to complex behavioural interventions ${ }^{(36)}$, older students might be less likely to change their habits since food preferences are formed early in life ${ }^{(37,38)}$. In addition, longer-standing behaviours are harder to be substituted by new ones ${ }^{(39)}$. Moreover, adolescents might already have experienced losses in games of chance and could therefore be less optimistic about the lottery outcome than younger children ${ }^{(40)}$.

Finally, the majority of students had never consumed these products prior to the intervention, but some had done so to a lesser or greater extent. Given that incentivizing the consumption of an already liked food item can undermine one's intrinsic motivation to purchase/consume it ${ }^{(41)}$ and/or potentially trigger satiation as a result of overconsumption, the available data set allowed us to assess the extent to which prior consumption moderated the impact of the intervention on students' purchasing behaviour, particularly in the long term. To capture the effect of past consumption behaviour heterogeneity, we compared the effects of the intervention across groups of students who had bought promoted products before the intervention with those who acquired them for the first time during the intervention. A dummy variable indicated whether the participant had (or had not) purchased a promoted product prior to the intervention.

\section{Statistical analysis}

A hierarchical linear model ${ }^{(42)}$ was used to examine the short- and long-term influence of the intervention on the purchasing of promoted products. Repeated observations were nested within participants and participants nested within schools in a three-level model to account for the non-independence of observations ${ }^{(43)}$. 
The outcome variable was aggregated at the individual level into three periods (before, during and after the intervention) to mitigate problems of serial autocorrelation $^{(44)}$. We first estimated a within-subjects model with the independent dummy variables for during- and postintervention period, which captured the change in consumption relative to the pre-intervention period.

Next, to estimate the short- and long-term effects of the intervention, within-subjects hierarchical linear models were estimated including data from all three intervention schools and having the dummy variables that indicate during- and post-intervention periods as the only predictors. In order to evaluate heterogeneous treatment effects, two-way interactions between indicator variables representing the duringand post-intervention periods and demographic or behavioural covariates $\left(Z_{i}\right)$ were considered, as follows:

$$
\begin{aligned}
Y= & \beta_{0}+\beta_{1} \text { DURING }+\beta_{2} \text { POST }+\beta_{3} Z_{i}+\beta_{4} \text { DURING } \times Z_{i} \\
& +\beta_{5} \text { POST } \times Z_{i}+e .
\end{aligned}
$$

To further refine the analysis, we compared the purchasing behaviour of students in the intervention schools with that of students from the control school, which allowed us to detach the effect of the intervention from seasonal variation or other unobserved events. Overall, 208 students used the company system to buy snacks in the cafeteria of the three treated schools, whereas 144 used this system at the control school during the period of interest. Therefore, to check for the robustness of the findings from within-subjects models, difference-in-differences models were estimated, including as predictors the indicator variable representing the treatment condition of the school, the during- and postintervention periods dummy variables and their interactions with the treatment dummy. Furthermore, heterogeneous treatment effects were estimated based on the following adjusted difference-in-differences model:

$$
\begin{aligned}
Y= & \beta_{0}+\beta_{1} \text { DURING }+\beta_{2} \text { POST }+\beta_{3} Z_{i}+\beta_{4} \text { TREAT } \\
& +\beta_{5} \text { DURING } \times Z_{i}+\beta_{6} \text { POST } \times Z_{i}+\beta_{7} D U R I N G \times \text { TREAT } \\
& +\beta_{8} \text { POST } \times \text { TREAT }+\beta_{9} Z_{i} \times \text { TREAT }+\beta_{10} \text { DURING } \times Z_{i} \\
& \times \text { TREAT }+\beta_{11} \text { POST } \times Z_{i} \times \text { TREAT }+e .
\end{aligned}
$$

In these models, the coefficients of interest are the threeway-interactions $\left(\beta_{10}\right.$ and $\left.\beta_{11}\right)$, which represent the heterogeneous effects of the intervention in the intervention schools (respectively in the short and long term) relative to the control school. For the sake of brevity, only these coefficients from the difference-in-differences models are reported in the text. Data analyses were performed with the statistical software package Stata version 13.1.

\section{Results}

\section{Descriptive statistics}

Table 1 presents the descriptive statistics of the participant students within intervention and control schools. Schools were judged to be comparable in terms of students' mean age and sex distribution. The company could not inform the total number of children and adolescents in each school at the time of the intervention. Since all students in each school are eligible to use the company's system, but not everyone does, we could not make any inferences on the magnitude of the students' engagement with the incentive programme. As observed, except for the number of participants, the control school presented demographic and purchase-related characteristics similar to at least one of the intervention schools.

\section{Overall effect}

A main effect of the treatment was observed in a withinsubjects assessment of the three intervention schools. The mean number of promoted products purchased daily per participant increased significantly during ( $v$. before) the intervention: $\beta=0.06, P<0.001$ (see Table 2). There was no evidence of a long-term effect. That is, the incentive did not impact the purchase of the promoted healthy items after the intervention period $(\beta=0.01, P=0.463)$. Additional analyses showed that the main effect of the intervention was significant for both moderate and high nutritional value promoted items during the intervention ( $\beta_{\text {mod }}=0.03, P<0.001$ and $\left.\beta_{\text {high }}=0.03, P<0.001\right)$, but not

\begin{tabular}{|c|c|c|c|c|c|c|c|c|}
\hline \multirow[b]{2}{*}{ Schools } & \multirow[b]{2}{*}{ No. of participants } & \multirow[b]{2}{*}{ Gender (\% female) } & \multicolumn{2}{|c|}{ Age (years) } & \multicolumn{2}{|c|}{$\begin{array}{l}\text { No. of items purchased } \\
\text { per transaction }\end{array}$} & \multicolumn{2}{|c|}{$\begin{array}{c}\text { Total value of the } \\
\text { purchase }(\mathrm{R} \$)\end{array}$} \\
\hline & & & Mean & SD & Mean & SD & Mean & SD \\
\hline $\begin{array}{l}\text { Control } \\
\text { Intervention }\end{array}$ & 144 & 46 & $10 \cdot 52$ & 1.91 & $1 \cdot 60$ & 0.83 & $5 \cdot 19$ & 2.77 \\
\hline $\begin{array}{l}11 \\
12 \\
\mid 3\end{array}$ & $\begin{array}{r}68 \\
102 \\
38\end{array}$ & $\begin{array}{l}55 \\
66 \\
47\end{array}$ & $\begin{array}{l}11.08 \\
10.11 \\
11.00\end{array}$ & $\begin{array}{l}2.63 \\
2.54 \\
2.83\end{array}$ & $\begin{array}{l}1.64 \\
2.04 \\
1.32\end{array}$ & $\begin{array}{l}0.80 \\
2.33 \\
0.52\end{array}$ & $\begin{array}{l}5.04 \\
4.58 \\
3.71\end{array}$ & $\begin{array}{l}2.63 \\
3.12 \\
1.73\end{array}$ \\
\hline
\end{tabular}
in the post-intervention period $\left(\beta_{\bmod }=0.00, P=0.632\right.$ and $\left.\beta_{\text {high }}=0.00, P=0.509\right)$, in line with the aggregated results.

Table 1 Demographic and purchasing characteristics of participants ( $n$ 352) across control and intervention schools participating in the lottery incentive intervention to promote the purchase of healthy products conducted in private primary- and secondary-school cafeterias in Belo Horizonte, Brazil, 2015

Values were calculated considering participants' behaviour prior to the intervention ( $\mathrm{R} \$$, Brazilian reais). 
Table 2 Hierarchical linear models (outcome variable: mean number of promoted products purchased daily per participant) assessing the impacts of the lottery incentive intervention to promote the purchase of healthy products conducted in private primary- and secondary-school cafeterias in Belo Horizonte, Brazil, 2015

\begin{tabular}{lcc}
\hline & & HLM \\
\cline { 2 - 2 } & & \\
Model/effect of interest & & SE \\
\hline Within-subjects model for intervention schools $(n$ 208) & & \\
During intervention & $0.060^{\star \star}$ & 0.011 \\
Post-intervention & 0.008 & 0.011 \\
Difference-in-differences model $(n$ 208) & & \\
Treatment & 0.023 & 0.032 \\
During intervention & 0.007 & 0.013 \\
Post-intervention & $0.042^{\star \star}$ & 0.013 \\
Treatment $\times$ during & $0.054^{\star \star}$ & 0.017 \\
Treatment $\times$ post & -0.033 & 0.017 \\
Heterogeneous treatment effects by age $(n$ 208) & & \\
During intervention & 0.018 & 0.023 \\
Post-intervention & 0.007 & 0.023 \\
Age & 0.007 & 0.022 \\
Age $\times$ during & $0.056^{\star}$ & 0.027 \\
Age $\times$ post & 0.001 & 0.027 \\
Heterogeneous treatment effects by sex $(n$ 208) & & \\
During intervention & 0.032 & 0.018 \\
Post-intervention & 0.014 & 0.018 \\
Sex & -0.011 & 0.019 \\
Sex $\times$ during & $0.047^{\star}$ & 0.023 \\
Sex $\times$ post & -0.009 & 0.023 \\
Heterogeneous treatment effects by past behaviour & & \\
( $n$ 208) & & 0.015 \\
During intervention & $0.058^{\star \star}$ & 0.015 \\
Post-intervention & 0.025 & 0.019 \\
Past behaviour & $0.075^{\star *}$ & 0.023 \\
Past behaviour $\times$ during & 0.005 & 0.023 \\
Past behaviour $\times$ post & -0.043 & \\
\hline
\end{tabular}

HLM, hierarchical linear model.

During treatment: $1=$ during the intervention period; $0=$ before the intervention period. Post-treatment: $1=$ after the intervention period; $0=$ before the intervention period. Age: $\langle 13$ years old/children $=1, \geq 13$ years old/adolescents $=0$. Sex: $1=$ female; $0=$ male. Past behaviour: $1=$ purchased promoted products before the intervention; $0=$ did not purchase promoted products before the intervention.

${ }^{\star} P<0.05,{ }^{\star \star} P<0.01$.

Three alternative outcomes were also analysed as robustness checks, including: (i) mean amount of Brazilian reais $(\mathrm{R} \$)$ spent daily per participant; (ii) mean number of choices of promoted products daily per participant (this metric does not consider the number of items bought in each purchase, but only if they were bought or not in a given purchase); and (iii) proportion of choices of promoted items over total choices per period per participant. Results were robust for the main effects of the intervention in the within-subjects and difference-in-differences models, for all additional outcomes (please refer to Supplemental Table 2 in online supplementary material).

To assess possible differences across the three intervention schools, a likelihood-ratio test was used comparing models with and without interactions between the time periods and dummy variables representing the schools. A significant effect was observed $\left(\chi_{(4)}^{2}=15 \cdot 58, P<0 \cdot 001\right)$. This effect resulted from a steeper increase in the consumption of the promoted products at school I3. Despite this difference, the purchase pattern of the promoted products resembled an inverted U-shaped curve in every single intervention school, which attests to the robustness of the effect.
A difference-in-differences model compared the pattern of purchase of promoted products between the intervention and control schools. A model using daily measures indicated parallel trends between intervention and control schools before the intervention, suggesting no significant differences in purchase patterns during that period. The results indicated that the coefficient of the interaction term between the indicator of treatment and the indicator of the period during the intervention was positive and statistically significant $(\beta=0.05, P=0.002$; see Table 2$)$, which means that there was an increase in the purchase of the promoted products in the intervention schools.

Figure 1 qualifies the effect by demonstrating a monotonic increase from the pre- to post-intervention period in the control school and an inverted U-shape in all three intervention schools. This finding supports the conclusion that the increase in the purchasing of promoted products was an effect of the intervention rather than a mere seasonal effect.

\section{Compensatory and complementary effects}

In order to explore potential compensatory effects, we divided the sample into two parts: (i) sub-sample 1, with 


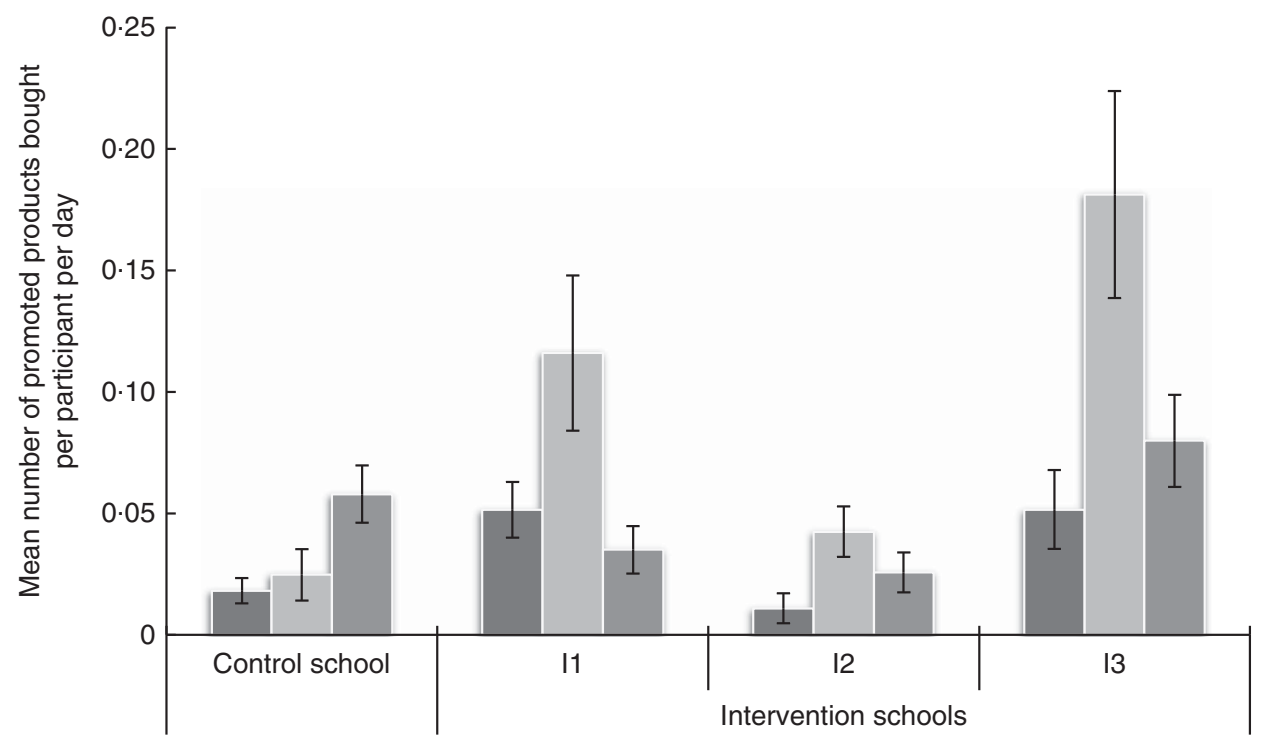

Fig. 1 Mean number of promoted products purchased daily per participant, with standard error of the mean represented by vertical bars, before ( $\square$ ), during ( $\square$ ) and after $(\square)$ the lottery incentive intervention to promote the purchase of healthy products conducted in private primary- and secondary-school cafeterias in Belo Horizonte, Brazil, 2015. A total of 352 students (208 in three intervention schools and 144 in one control school) were included in the final analyses

those students who consumed at least one promoted product during the intervention ( $n$ 61); and (ii) sub-sample 2 , including those who did not respond to the intervention. We did so as compensatory effects might only occur among those who, in fact, purchased the promoted product as a consequence of the intervention. We observed in sub-sample 1 that there was a main effect of the intervention in the short term on the total number of products purchased daily at the school cafeteria $(\beta=0 \cdot 41, P=0 \cdot 001)$ and on the total number of non-promoted healthier items ( $\beta=0.12, P=0.002)$, but also on the number of low nutritional value items $(\beta=0 \cdot 12, P=0 \cdot 015)$. There was no significant change in the total amount of purchased products among students from sub-sample $2(\beta=-0.04$, $P=0.527)$. A more detailed analysis of the consumption of the students from sub-sample 1 indicated that the increase in their consumption of non-promoted products during the intervention derived only from non-promoted beverages $(\beta=0.04, P=0.010)$, but not from non-promoted products other than beverages $(\beta=-0.01, P=0.820)$. This effect may be explained by complementary consumption of drinks in addition to solid items since, except for orange juice, none of the promoted items were beverages.

\section{Age and sex in the short term}

The short-term impact of the intervention varied by age $(\beta=0.06, \quad P=0.036)$ and $\operatorname{sex}(\beta=0.05, \quad P=0.043$; see Table 2). Children younger than 13 years of age had a better response to the intervention $\left(\right.$ mean $_{\mathrm{pre}}=0.03$, $\mathrm{SD}=0.08 v$. mean $\left._{\text {during }}=0.10, \mathrm{SD}=0.22 ; \beta=0.08, P<0.001\right)$ compared with those aged 13 years or above $\left(\right.$ mean $_{\text {pre }}=0.03$, $\mathrm{SD}=0.08 v$. mean $\left._{\text {during }}=0.05, \mathrm{SD}=0.13 ; \beta=0.02, P=0.455\right) . \mathrm{A}$ three-way interaction between the indicator variable representing the treatment condition of the school, the period during the intervention and age was statistically significant $(\beta=0.13, P=0.003)$, suggesting that the effect was robust when the intervention schools were compared with the control school.

Similarly, girls were more sensitive to the intervention $\left(\right.$ mean $_{\text {pre }}=0.02, \mathrm{SD}=0.07 v$. mean $_{\text {during }}=0.10, \mathrm{SD}=0.23$; $\beta=0.08, P<0.001)$ compared with boys $\left(\right.$ mean $_{\text {pre }}=0.04$, $\mathrm{SD}=0.10 \quad v . \quad \operatorname{mean}_{\text {during }}=0.07, \quad \mathrm{SD}=0.16 ; \quad \beta=0.03$, $P=0 \cdot 070$ ). However, this time the three-way interaction term between the treatment condition of the school, the period during the intervention and sex was not significant $(\beta=0.07, P=0.053)$.

\section{Past behaviour in the short term}

As displayed in Table 2, the short-term impact of the incentive did not interact with past purchase $(\beta=0.01$, $P=0.822$ ). The difference-in-difference model yielded similar results with a non-significant three-way interaction ( $\beta=0.01, P=0.877)$. During the intervention, the incentive programme was effective irrespective of the frequency with which a participant purchased promoted products prior to the intervention.

It is worth noting, however, that contrary to the main effect of incentives on consumption of targeted healthy items during the intervention period, the interacting role of age, sex and past behaviour did not pass the robustness check of alternative outcome variables. That is, heterogeneous treatment effects were sensitive to the specific dependent variable at stake (please refer to online supplementary material). 


\section{Long-term effects}

No significant difference between pre- and postintervention consumption was noted in the intervention schools $(\beta=-0.03, \quad P=0.052)$ in the difference-indifferences model. Additionally, a supplemental analysis identified a non-significant linear trend of the daily number of promoted products purchased in the postintervention period $(\beta=0.00, P=0.080)$. Put simply, the removal of a nine-weekday incentive programme reduced the purchase of the promoted products to pre-intervention levels almost immediately, and purchases remained at low levels.

\section{Age and sex in the long term}

The long-term impact of the intervention on healthier eating did not vary by age $(\beta=0.00, P=0.964)$ or sex $(\beta=-0.01, P=0.710)$. These results were consistent at the three-way interaction model for both age $(\beta=0.06$, $P=0 \cdot 170)$ and $\operatorname{sex}(\beta=0 \cdot 02, P=0 \cdot 506)$.

\section{Past behaviour in the long term}

The long-term impact of the intervention did not vary as a function of past behaviour $(\beta=-0.04, P=0.066)$. The three-way interaction model revealed similar results $(\beta=0 \cdot 06, P=0 \cdot 111)$.

\section{Discussion}

The present study assessed the effect of a lottery-based incentive on the purchase of healthy food by children and adolescents in school cafeterias. Besides some wellfounded scepticism on the role of schools-based interventions on obesity prevention ${ }^{(45,46)}$, we found that students responded to the intervention in the short term, as expected. However, no long-term effect was observed. Although the incentive promoted a temporary positive shift, it did not form a habit. Why was the incentive so ineffective in the long term? Several aspects might have affected the results. However, we believe that there are at least two elements to consider when compared with other studies in this area: (i) the duration of the intervention period; and (ii) the format of the incentive.

The intervention used in the present study lasted only nine weekdays. This was a rather short period of time compared with studies that observed lingering effects $^{(19,21,47-49)}$. Indeed, the higher efficacy of longer programmes was supported by a review of field experiments that assessed the effect of economic incentives in changing eating behaviour ${ }^{(50)}$. Out of the seven studies that included follow-up periods, three studies observed sustained improvement after the intervention period (duration of the programmes: 5 to 24 weeks, 24-week follow-up, none regarding school settings or children), whereas four of them did not identify any lasting effect (duration of the programmes: 3 to 12 weeks, 3- to 24-week follow-up, one of them in a school setting), roughly suggesting that habits could be built after longer exposures. The intervention used in our study lasted for significantly less time than any of the other studies. Hence, it is possible that a 'minimum duration threshold' is required for any lasting effect to be observed.

In our study, the incentive was formatted as a lottery. Current literature suggests that for habits to form, responses must become tied to features of performance contexts and not to the rewarding outcomes ${ }^{(51)}$. Moreover, the reinforcement schedule embedded in lottery incentives tends to produce goal-directed behaviour, which is typically associated with cessation of the behaviour if the reward is absent ${ }^{(52)}$. This notion could partly be the reason why many of the described studies (ours included) were not able to demonstrate consistent and long-standing habit formation in the samples studied. Nevertheless, it did have an effect in the short term. Considering that people on average overestimate small probabilities ${ }^{(53)}$, formatting an economic incentive as a lottery might be a scalable, costeffective intervention if the expected goal is, for example, a one-time behaviour, such as exposing children to a new healthy food for the first time.

Finally, students who engaged in the promotion bought more products, and more unhealthy products. The effect of the incentive on students' behaviour could elicit one of two possibilities: (i) children and adolescents could either buy the promoted products in addition to their other habitual choices; or (ii) they could substitute a given product for the promoted ones. Although addition would be an obviously unintended consequence given the potential increase in energy intake, substitution would only push towards a healthier track if unhealthy products were being substituted for the promoted, healthier ones. Being informed that the products promoted were healthier, participants might have compensated their intake by choosing less healthy, more energy-dense snacks. Moreover, having already chosen the healthier option, students might have allowed themselves to indulge in a less healthy treat $^{(54)}$. Another possible explanation relies on the fact that beverages were the only category responsible for the increase in the purchase of less healthy items during the intervention, which may indicate a complementary consumption of drinks to solid promoted items (such as ham and cheese pastry or burger on a wholegrain bun).

\footnotetext{
Age

The literature has reported surprisingly mixed findings on the impact of age on behaviour change. Kropski et al. ${ }^{(55)}$ found that programmes including younger children (7-10 years) were generally not effective in reducing BMI or obesity prevalence, whereas older children (10-14 years) demonstrated positive outcomes. Budd and Volpe ${ }^{(56)}$ also suggested that programmes targeting older children were more successful potentially because older age might make
} 
students more amenable to behaviour change. In contrast, a meta-analysis by Cook-Cottone et al. ${ }^{(57)}$ found that interventions that targeted younger children were the most effective. Lastly, a meta-analysis found no difference across age groups ${ }^{(31)}$. In the most recent field experiments on the effect of incentives on eating behaviour (varied age ranges, roughly between 6 and 14 years), although some studies observed better responses for younger children ${ }^{(19,58)}$, others found the opposite results ${ }^{(24,59,60)}$.

In our study, there is some evidence that the short-term effect of the incentives programme was stronger for children compared with adolescents. Although the exact reasons for this effect are unclear, it is worth mentioning at least two possibilities. On the one hand, the fact that younger children $(<13$ years) responded better to the intervention is consistent with the notion that it is easier to change the behaviour of younger ( $v$. older) people. However, we cannot exclude the alternative explanation that this particular group was simply more sensitive to the type of incentive being offered (e.g. board games such as Monopoly and Guess Who?).

\section{Sex}

Evidence from the current literature on sex-specific response to behavioural change programmes towards healthier lifestyles is also inconclusive. A meta-analysis by Cook-Cottone et al. ${ }^{(57)}$ found that although mixed-gender interventions had an overall significantly positive effect, female-only oriented interventions had mixed outcomes. Kropski et al. ${ }^{(55)}$ assessed the effect of school-based programmes on obesity prevention and suggested that those that were based on educational components built over social learning would be more appropriate for girls, whereas structural and environmental interventions enabling physical activity would be more effective for boys. From the most recent field experiments on the effect of incentives, Loewenstein et $_{\text {al }}{ }^{(19)}$ did not notice sex differences during the intervention but found that boys had a slightly lower level of habit formation, whereas Just and Price ${ }^{(24)}$ found that girls responded better to their intervention. List and Samek ${ }^{(59)}$ and Belot et al. ${ }^{(60)}$ found no considerable sex differences.

We found only weak evidence that girls responded better to the intervention in the short term and the effect varied depending on the outcome measure used. One possible reason for this effect is that the message conveyed by the promotion of healthier eating habits alluded to weight- and body-image-related issues, a matter that girls are more sensitive to ${ }^{(31,32)}$. Another reason could be the alimentary nature of the intervention, which is a less appealing incentive for males. Finally, the girls in our sample might also have become more interested in the rewards offered.

\section{Past behaviour}

Students who had habitually purchased the promoted items prior to the incentives intervention and those who had not responded to the intervention in a similar way in both during- and post-intervention periods. This null effect deserves attention since previous research results suggest that the use of incentives may undermine intrinsic motivation if the target product is already liked ${ }^{(41,61)}$. In line with more recent evidence that the use of incentives to promote health behaviour might be impervious to the crowd-out effect ${ }^{(62,63)}$, the findings from the present quasiexperiment suggest that the decrease in the choice of previously bought products may be due to a regression toward the mean ${ }^{(64,65)}$. Further studies should employ designs that allow for past behaviour assessment and longer follow-up periods in order to further identify the emergence of the crowd-out effect when health behaviour is being incentivized.

\section{Limitations}

Our study had a few key limitations. First, the causal inference was limited by the lack of random assignment of the intervention. However, the adopted pre-post design controls for the effect of time-invariant confounders and the inclusion of a control school in a difference-in-differences model accounts for the potential effect of seasonal or other external events during the intervention, reinforcing the robustness of the findings. Second, no information on actual consumption was available. Thus, we do not know whether students' choices and purchases were actually eaten. Third, we did not have access to purchases made in cash in the cafeteria. We are aware that the debit-card system is the preferred method of paying for snacks, but it is not exclusive. Fourth, the increase in purchasing of the promoted healthy items might not have been related to the incentive itself, but simply due to the fact that they were put in evidence, an effect that our study was unable to disentangle. Lastly, the present study discussed the results of an intervention that took place in private schools in the Southeast of Brazil. Although we are aware that private schools are a niche market, which might limit the reach of our findings, it represents a non-negligible population of approximately nine million students, roughly $25 \%$ of school-age children and adolescents in Brazil ${ }^{(66)}$. Nevertheless, we believe that our findings are potentially replicable in public schools, especially given the scalability and cost-effectiveness of lottery incentives.

\section{Conclusion}

The present study reports the results of a lottery-based incentive programme tested using data from a quasiexperiment. Within the programme, we test the effectiveness of an incentive conditional on the purchase of healthy promoted items on the short- and long-term influence on healthier products purchasing behaviour. We also perform a subgroup analysis to detect different patterns of 
response to the programme across sex, age and previous purchasing behaviour. We find evidence of a short-term effect of the intervention that is particularly effective among younger students. Long-lasting effects of the intervention were not observed after the incentives were suspended, which begs the question of whether a 'minimum duration threshold' is required for any lasting effect to be observed. We did not find a crowd-out effect among those students who already used to buy the products that were then promoted during the intervention. Furthermore, students who responded to the promotion bought more products overall, but also more of the unhealthy products, an obvious unintended consequence of an intervention designed to stimulate healthier eating behaviour.

Importantly, as we move to a cashless society and face the health consequences associated with it ${ }^{(67)}$, we believe that the described debit-card system allows for multiple interventions to be tested simultaneously or in tandem, with low marginal costs, in addition to discreetly collecting secondary data. This may help elucidate the configurations of incentive programmes that, alone or in association with other interventions ${ }^{(68)}$, could lead to most-wanted, longlasting behavioural change and explore boundary conditions for new habits to emerge.

These results underscore the need for a better understanding of the role of economic incentives in building longlasting behavioural change towards healthy eating. Consistent with other research that assesses the impact of incentives in health and education-related behaviour, we maintain that discussion should go beyond whether incentives work but rather when and why they do and do not work $^{(69)}$ and, just as important, for whom and for how long.

\section{Supplementary material}

To view supplementary material for this article, please visit https://doi.org/10.1017/S1368980019000223

\section{Acknowledgements}

Acknowledgements: The authors would like to thank the people at Nutrebem for their collaborative effort, and the Center for Behavioral Research at FGV/EBAPE for their continuous support. The authors would also like to thank Daniel Mochon for his insightful comments on an earlier version of this manuscript. Financial support: This research received no specific grant from any funding agency in the public, commercial or not-for-profit sectors. Conflict of interest: None. Authorship: C.M.F. and R.G. contributed equally to the conception and design of the project, and the acquisition, analysis and interpretation of data for the work. E.B.A. contributed to the conception and design of the project and the interpretation of data, and also reviewed/ revised it critically for important intellectual content. Ethics of human subject participation: Ethical approval to independently analyse the data was obtained from the institutional research committee (\#06102015-1701) as well as the company (Technical Cooperation Term \#09062015). Students' anonymity was preserved.

\section{References}

1. Klerman JA, Bartlett S, Wilde P et al. (2014) The short-run impact of the Healthy Incentives Pilot Program on fruit and vegetable intake. Am J Agric Econ 96, 1372-1382.

2. Swinburn BA, Caterson I, Seidell JC et al. (2004) Diet, nutrition and the prevention of excess weight gain and obesity. Public Health Nutr 7, 123-146.

3. Roberto CA, Swinburn B, Hawkes C et al. (2015) Patchy progress on obesity prevention: emerging examples, entrenched barriers, and new thinking. Lancet 385, 2400-2409.

4. Malik VS, Willett WC \& Hu FB (2013) Global obesity: trends, risk factors and policy implications. Nat Rev Endocrinol 9, $13-27$.

5. Wang Y \& Lobstein T (2006) Worldwide trends in childhood overweight and obesity. Int J Pediatr Obes 1, 11-25.

6. Instituto Brasileiro de Geografia e Estatística (2016) Pesquisa Nacional de Saúde do Escolar 2015. https://biblioteca.ibge. gov.br/visualizacao/livros/liv97870.pdf (accessed October 2018).

7. Niehues JR, Gonzales AI, Lemos RR et al. (2014) Prevalence of overweight and obesity in children and adolescents from the age range of 2 to 19 years old in Brazil. Int J Pediatr 2014, 583207.

8. Lien N, Lytle LA \& Klepp K-I (2001) Stability in consumption of fruit, vegetables, and sugary foods in a cohort from age 14 to age 21. Prev Med 33, 217-226.

9. Gortmaker SL, Wang YC, Long MW et al. (2015) Three interventions that reduce childhood obesity are projected to save more than they cost to implement. Health Aff (Millwood) 34, 1932-1939.

10. Story M, Nanney MS \& Schwartz MB (2009) Schools and obesity prevention: creating school environments and policies to promote healthy eating and physical activity. Milbank Q 87, 71-100.

11. Khambalia AZ, Dickinson S, Hardy LL et al. (2012) A synthesis of existing systematic reviews and meta-analyses of school-based behavioural interventions for controlling and preventing obesity. Obes Rev 13, 214-233.

12. Wang Y, Wu Y, Wilson RF et al. (2013) Childhood Obesity Prevention Programs: Comparative Effectiveness Review and Meta-Analysis. Rockville, MD: Agency for Healthcare Research and Quality.

13. Wood W \& Rünger D (2016) Psychology of habit. Annu Rev Psychol 67, 289-314

14. Howerton MW, Bell BS, Dodd KW et al. (2007) Schoolbased nutrition programs produced a moderate increase in fruit and vegetable consumption: meta and pooling analyses from 7 studies. J Nutr Educ Behav 39, 186-196.

15. Charness G \& Gneezy U (2009) Incentives to exercise. Econometrica 77, 909-931.

16. Lowe CF, Horne PJ, Tapper K et al. (2004) Effects of a peer modelling and rewards-based intervention to increase fruit and vegetable consumption in children. Eur J Clin Nutr 58, 510-522.

17. Volpp KG, John LK, Troxel AB et al. (2008) Financial incentive-based approaches for weight loss: a randomized trial. JAMA 300, 2631-2637.

18. Jensen JD, Hartmann H, De Mul A et al. (2011) Economic incentives and nutritional behavior of children in the school setting: a systematic review. Nutr Rev 69, 660-674. 
19. Loewenstein G, Price J \& Volpp K (2016) Habit formation in children: evidence from incentives for healthy eating. J Health Econ 45, 47-54.

20. Mochon D, Schwartz J, Maroba J et al. (2016) Gain without pain: the extended effects of a behavioral health intervention. Manage Sci 63, 58-72.

21. Morrill BA, Madden GJ, Wengreen HJ et al. (2016) A randomized controlled trial of the Food Dudes Program: tangible rewards are more effective than social rewards for increasing short-and long-term fruit and vegetable consumption. J Acad Nutr Diet 116, 618-629.

22. Corsini N, Slater A, Harrison A et al. (2013) Rewards can be used effectively with repeated exposure to increase liking of vegetables in 4-6-year-old children. Public Health Nutr 16, 942-951.

23. Bere E, te Velde SJ, Småstuen MC et al. (2015) One year of free school fruit in Norway -7 years of follow-up. Int $J$ Behav Nutr Phys Act 12, 1.

24. Just DR \& Price J (2013) Using incentives to encourage healthy eating in children. J Hum Resour 48, 855-872.

25. Wansink B \& Hanks AS (2014) Calorie reductions and within-meal calorie compensation in children's meal combos. Obesity (Silver Spring) 22, 630-632.

26. Wisdom J, Downs JS \& Loewenstein G (2010) Promoting healthy choices: information versus convenience. Am Econ J Appl Econ 2, 164-178.

27. Birch LL, Johnson SL, Jones MB et al. (1993) Effects of a nonenergy fat substitute on children's energy and macronutrient intake. Am J Clin Nutr 58, 326-333.

28. Birch LL, McPhee LS, Bryant JL et al. (1993) Children's lunch intake: effects of midmorning snacks varying in energy density and fat content. Appetite 20, 83-94.

29. Drewnowski A (2010) The nutrient rich foods index helps to identify healthy, affordable foods. Am J Clin Nutr $\mathbf{9 1}$, issue 4, 1095S-1101S.

30. French SA, Story M, Jeffery RW et al. (1997) Pricing strategy to promote fruit and vegetable purchase in high school cafeterias. J Acad Nutr Diet 97, 1008-1010.

31. Stice E, Shaw H \& Marti CN (2006) A meta-analytic review of obesity prevention programs for children and adolescents: the skinny on interventions that work. Psychol Bull 132, 667-691.

32. Abramovitz BA \& Birch LL (2000) Five-year-old girls' ideas about dieting are predicted by their mothers' dieting. $J \mathrm{Am}$ Diet Assoc 100, 1157-1163.

33. Hillier LM \& Morrongiello BA (1998) Age and gender differences in school-age children's appraisals of injury risk. $J$ Pediatr Psychol 23, 229-238.

34. Liben LS \& Bigler RS (2014) Advances in Child Development and Behavior. vol. 47: The Role of Gender in Educational Contexts and Outcomes. London: Elsevier.

35. Hardoon KK \& Derevensky JL (2002) Child and adolescent gambling behavior: current knowledge. Clin Child Psychol Psychiatry 7, 263-281.

36. Baranowski T, Cullen KW, Nicklas T et al. (2002) Schoolbased obesity prevention: a blueprint for taming the epidemic. Am J Health Behav 26, 486-493.

37. Schwartz C, Scholtens PAMJ, Lalanne A et al. (2011) Development of healthy eating habits early in life. Review of recent evidence and selected guidelines. Appetite 57, 796-807.

38. Birch LL \& Fisher JO (1998) Development of eating behaviors among children and adolescents. Pediatrics 101, 539-549.

39. Lustig C, Konkel A \& Jacoby LL (2004) Which route to recovery? Controlled retrieval and accessibility bias in retroactive interference. Psychol Sci 15, 729-735.

40. Bjorklund DF \& Green BL (1992) The adaptive nature of cognitive immaturity. Am Psychol 47, 46-54.
41. Cooke LJ, Chambers LC, Añez E V et al. (2011) Eating for pleasure or profit: the effect of incentives on children's enjoyment of vegetables. Psychol Sci 22, 190-196.

42. Warne RT, Li Y, McKyer ELJ et al. (2012) Managing clustered data using hierarchical linear modeling. J Nutr Educ Behav 44, 271-277.

43. Raudenbush SW \& Bryk AS (2002) Advanced Quantitative Techniques in the Social Sciences. vol. 1: Hierarchical Linear Models: Applications and Data Analysis Methods. Thousand Oaks, CA: SAGE Publications, Inc.

44. Bertrand M, Duflo E \& Mullainathan S (2002) How Much Should We Trust Differences-in-Differences Estimates? Cambridge, MA: National Bureau of Economic Research.

45. Lytle LA (2009) School-based interventions: where do we go next? Arch Pediatr Adolesc Med 163, 388-389.

46. Gittelsohn J \& Kumar MB (2007) Preventing childhood obesity and diabetes: is it time to move out of the school? Pediatr Diabetes 8, 55-69.

47. Bere E, Veierød MB \& Klepp K-I (2005) The Norwegian School Fruit Programme: evaluating paid vs. no-cost subscriptions. Prev Med 41, 463-470.

48. Bere E, Veierød MB, Bjelland M et al. (2006) Free school fruit - sustained effect 1 year later. Health Educ Res 21, 268-275

49. Bere E, Veierød MB, Skare $\varnothing$ et al. (2007) Free school fruit sustained effect three years later. Int J Behav Nutr Phys Act 4, 1.

50. An R (2013) Effectiveness of subsidies in promoting healthy food purchases and consumption: a review of field experiments. Public Health Nutr 16, 1215-1228.

51. Wood W \& Neal DT (2009) The habitual consumer. J Consum Psychol 19, 579-592.

52. Yin HH \& Knowlton BJ (2006) The role of the basal ganglia in habit formation. Nat Rev Neurosci 7, 464-476.

53. Kahneman D \& Tversky A (1979) Prospect theory: an analysis of decision under risk. Econometrica 47, 263-292.

54. Finkelstein SR \& Fishbach A (2010) When healthy food makes you hungry. J Consum Res 37, 357-367.

55. Kropski JA, Keckley PH \& Jensen GL (2008) School-based obesity prevention programs: an evidence-based review. Obesity (Silver Spring) 16, 1009-1018.

56. Budd GM \& Volpe SL (2006) School-based obesity prevention: research, challenges, and recommendations. J Sch Health 76, 485-495.

57. Cook-Cottone C, Casey CM, Feeley TH et al. (2009) A metaanalytic review of obesity prevention in the schools: 19972008. Psychol Sch 46, 695-719.

58. Lowe CF, Horne PJ, Tapper K et al. (2004) Effects of a peer modelling and rewards-based intervention to increase fruit and vegetable consumption in children. Eur J Clin Nutr $\mathbf{5 8}$, 510-522.

59. List JA \& Samek AS (2015) The behavioralist as nutritionist: leveraging behavioral economics to improve child food choice and consumption. $J$ Health Econ 39, 135-146.

60. Belot MM, James J \& Nolen PJ (2014) Incentives and children's dietary choices: a field experiment in primary schools. J Health Econ 50, 213-229.

61. Cooke LJ, Chambers LC, Añez E V et al. (2011) Facilitating or undermining? The effect of reward on food acceptance. A narrative review. Appetite 57, 493-497.

62. Gardiner CK \& Bryan AD (2017) Monetary incentive interventions can enhance psychological factors related to fruit and vegetable consumption. Ann Behav Med 51, 599-609.

63. Sen AP, Huffman D, Loewenstein G et al. (2016) Do financial incentives reduce intrinsic motivation for weight loss. In Nudging Health: Health Law and Behavioral Economics, pp. 202-216 [IG Cohen, HF Lynch and CT Robertson, editors]. Baltimore, MD: Johns Hopkins University Press. 
64. Yu R \& Chen L (2015) The need to control for regression to the mean in social psychology studies. Front Psychol $\mathbf{5}$, 1574 .

65. Barnett AG, Van Der Pols JC \& Dobson AJ (2005) Regression to the mean: what it is and how to deal with it. Int J Epidemiol 34, 215-220.

66. Instituto Nacional de Estudos e Pesquisas Educacionais Anísio Teixeira (2018) Sinopse Estatística da Educação Básica 2017. http://portal.inep.gov.br/sinopses-estatisticasda-educacao-basica (accessed October 2018).
67. Thomas M, Desai KK \& Seenivasan S (2011) How credit card payments increase unhealthy food purchases: visceral regulation of vices. J Consum Res 38, 126-139.

68. Rogers T \& Frey E (2015) Changing behavior beyond the here and now. In The Wiley-Blackwell Handbook of Judgment and Decision Making, pp. 723-748. Chichester: John Wiley \& Sons Ltd.

69. Gneezy U, Meier S \& Rey-Biel P (2011) When and why incentives (don't) work to modify behavior. J Econ Perspect 25, 191-210. 